\title{
A utilizaçáo de órteses de membro superior em pacientes com artrite reumatoide: uma revisão de literatura no campo da terapia ocupacional
}

\author{
Talita Silvério de Souza Silva, Lilian Dias Bernardo Massa \\ Instituto Federal de Educação, Ciência e Tecnologia do Rio de Janeiro - IFRJ, Rio de Janeiro, RJ, Brasil.
}

\begin{abstract}
Resumo: Introdução: A artrite reumatoide é uma desordem crônica e sistêmica, que acomete com mais frequência pequenas articulações, como as das mãos e dos punhos. Pode causar deformidades que comprometem a função manual, com impacto no desempenho ocupacional do sujeito. Para auxiliar na restauração da função manual, Terapeutas Ocupacionais, frequentemente, utilizam as órteses a fim de favorecer a autonomia e/ou a independência para realizar as atividades cotidianas dos pacientes com artrite reumatoide. Objetivo: O estudo teve por objetivos identificar as pesquisas sobre órteses de membro superior utilizadas em pessoas com artrite reumatoide e que foram assistidas pela terapia ocupacional, caracterizando a população, o tipo de pesquisa e os desfechos obtidos. Métodos: É um estudo de revisão de literatura e, como critérios de seleção, buscou-se por artigos dos últimos dez anos, nos idiomas inglês, espanhol e português, através de pesquisas do tipo experimentais, observacionais ou relato de caso, em pacientes com artrite reumatoide e que foram assistidos por um Terapeuta Ocupacional. Foram selecionados 12 artigos para revisão. Resultados: A revisão de literatura aponta os benefícios encontrados pelo uso da órtese, no que se refere a destreza manual, força de preensão e alívio da dor, e aos aspectos relacionados ao conforto e à satisfação do paciente. Conclusão: Nesse contexto, a órtese surge como um recurso de tecnologia assistiva importante para a manutenção da função e o resgate das atividades que estavam comprometidas.
\end{abstract}

Palavras-chave: Terapia Ocupacional, Artrite Reumatoide, Dispositivos Assistivos.

\section{The use of upper limb orthoses in patients with rheumatoid arthritis: a literature review in the field of occupational therapy}

\begin{abstract}
Introduction: Rheumatoid arthritis is a chronic systemic disease that most often affects smaller joints such as hands and wrists. It may cause deformities that jeopardize hand function, thus impacting the subject occupational performance. In order to assist the hand function restoration, occupational therapists often use orthosis to improve autonomy and/or independence to perform daily activities in patients with rheumatoid arthritis. Objective: This study aimed to identify the upper limb's orthoses used in patients with rheumatoid arthritis, who were assisted by the Occupational Therapy, featuring the population, the type of research and the outcomes obtained. Method: This study is literature review and its selection criteria consists of publications in English, Spanish and Portuguese published within the last ten years, divided between experimental, observational and case studies, all with diagnosis of rheumatoid arthritis and assisted by an occupational therapist. Twelve articles were selected for review. Findings: The literature review points out the benefits achieved through the use of the orthosis to manual dexterity, grip strength, pain relief and aspects related to comfort and patient satisfaction. Conclusion: In this context, the orthosis appears as an important assistive technology resource to keep function and restore compromised activities.
\end{abstract}

Keywords: Occupational Therapy, Rheumatoid Arthritis, Self-Help Devices.

Autor para correspondência: Lilian Dias Bernardo Massa, Instituto Federal de Educação, Ciência e Tecnologia do Rio de Janeiro, Rua Professor Carlos Wenceslau, 343, Realengo, CEP 21715-000, Rio de Janeiro, RJ, Brasil, e-mail: lilian.bernardo@ifrj.edu.br

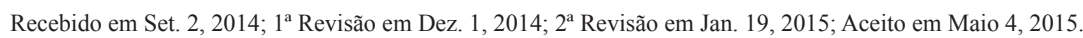




\section{Introdução}

Artrite Reumatoide (AR) é uma doença autoimune, crônica e sistêmica, que tem como característica clínica mais evidente a inflamação da membrana sinovial, estrutura presente na cápsula articular e nos tendôes, com a função de lubrificar e levar nutrientes para essa regiāo (BUCKNER, 2005). Nessa doença, a membrana está repleta de células inflamatórias e de novos vasos, e passa a ser chamada de pannus sinovial. A invasão e a proliferação do pannus gera a destruição das estruturas que, normalmente, a membrana deveria proteger (SILVA; MEIRELES; NATOUR, 2010).

Para diagnosticar a AR, preconiza-se o aparecimento de quatro dos sete sintomas relacionados à doença, como: rigidez matinal, poliartrite, artrite nas mãos, acometimento simétrico, nódulos reumatoides, fator reumatoide sérico e alteraçôes radiográficas. Esses sintomas precisam estar presentes por pelo menos seis semanas (LAURINDO et al., 2004).

A doença apresenta-se com uma prevalência de $1 \%$ da população mundial, com uma maior probabilidade na faixa etária de 30 a 50 anos (MOREIRA; CARVALHO, 2003 apud CAVALCANTI, 2006). Em casos de a doença se iniciar em crianças menores de 16 anos, é chamada de artrite reumatoide juvenil (ARAÚJO, 2006).

No Brasil, um estudo feito pelo Ministério da Saúde relata uma prevalência nacional de $0,46 \%$, que representa quase um milhão de indivíduos, sendo predominante nas mulheres, entre a quarta e a sexta décadas de vida (BRASIL, 2013). Ao acometer os homens, é mais comum o aparecimento da doença entre a sexta e a oitava décadas de vida (O'DELL, 2008).

A doença evolui com alteraçôes articulares e/ou periarticulares e, em menor frequência, extra-articulares. Nas manifestações articulares, pode-se observar o acometimento simétrico e poliarticular (CARVALHO; BÉRTOLO, 2008). Há uma fragilidade nas articulaçóes acometidas pela AR, pois o pannus promove erosóes ósseas e subcondral, além de predispor à instabilidade da parte ligamentar e/ou tendínea, o que pode levar a rupturas destas estruturas (O'DELL, 2008).

À medida que a doença progride, há o aparecimento de deformidades articulares e as mais comumente apresentadas, no membro superior, são: desvio ulnar dos dedos, dedos em fuso, dedos em pescoço de cisne, dedo em botoeira, polegar em $\mathrm{Z}$ e mão em dorso de camelo (ARAÚJO, 2006). A instalação das deformidades está associada a diminuição da amplitude de movimento, perda de força muscular, aumento da dor e diminuição do desempenho físico, e ao comprometimento na realização das atividades cotidianas (BUENO et al., 2007). Em geral, pacientes com essa patologia reumática experimentam limitaçôes funcionais que restringem a participação e o envolvimento nas áreas de ocupação (SILVA; MEIRELES; NATOUR, 2010).

Devido às alterações no desempenho ocupacional, o Terapeuta Ocupacional, tradicionalmente, irá trabalhar com pacientes com artrite reumatoide (AR), com o propósito de possibilitar a realização das atividades com autonomia, prevenir perdas de função e/ou manutenção da função manual (HAMMOND; YOUNG; KIDAO, 2004 apud NOORDHOEK; LOSCHIAVO, 2007).

Dentre os recursos utilizados por este profissional, destacam-se os produtos assistivos - entre os quais, as órteses -, que possibilitam uma maior funcionalidade na realização e na participação das atividades cotidianas, mesmo na presença de incapacidades e limitações (BRASIL, 2007). As órteses são instrumentos externos e auxiliam na melhora e/ou na correção da função perdida/limitada dos membros (WASSERTEIN; CHAMLIAM, 2010). Quanto à funcionalidade, as órteses podem ser estáticas ou dinâmicas (CARVALHO, 2006a).

Os indivíduos com AR podem se beneficiar do uso desse recurso para aumentar ou manter a capacidade funcional - favorecendo a amplitude de movimento (ADM), o alinhamento correto do membro, a estabilização da articulação e a diminuiçáo da dor - necessária durante a realização das atividades rotineiras (EGAN, 2010).

Considerando-se as informaçóes expostas e a pouca literatura encontrada sobre o tema, o presente estudo teve por objetivos identificar as pesquisas sobre órteses de membro superior utilizadas em pessoas com artrite reumatoide e que foram assistidas pela terapia ocupacional, caracterizando a população, o tipo de pesquisa e os desfechos obtidos.

\section{Métodos}

Este estudo constitui-se de revisão narrativa da literatura. O levantamento dos artigos científicos foi feito por meio de buscas nas bases de dados PubMed - indexed for MEDLINE, LILACS, Scielo, Web of Science, Cross Ref, Scirus, Scopus e Cochrane, no período de março a dezembro de 2013. Para tanto, foram utilizados os seguintes termos de busca: artrite reumatoide, órtese, splint e terapia ocupacional. Durante a busca nas bases de dados, os termos foram combinados de dois em dois. 
A seleção dos artigos obedeceu aos seguintes critérios: (a) artigos científicos nos idiomas português, espanhol e inglês; (b) publicaçôes compreendidas no período de 2003 a 2013; (c) estudos do tipo experimentais, observacionais ou relato de caso; (d) diagnóstico de artrite reumatoide; (e) ter Terapeuta Ocupacional na autoria; (f) sem restrição quanto ao tempo de evolução da doença e $(\mathrm{g})$ sem restrição quanto à adesão do paciente. Para análise e sistematização dos dados, os artigos utilizados foram lidos na íntegra e foram colhidas informaçôes sobre os tipos de órteses, seus papéis e os resultados da utilização nessa clientela.

\section{Resultados e discussão}

Foram encontrados 195 artigos. Destes, 46 foram separados pelo título e somente 12 se relacionavam à pesquisa. Nenhum artigo em espanhol estava relacionado ao tema.

A Tabela 1 retrata as características da população dos 12 estudos selecionados, na qual se registram o número de participantes, a média das idades e as deformidades e/ou os problemas associados à AR.

Nos estudos, a maioria dos participantes era do sexo feminino, o que é previsto na literatura, pois esta aponta para a proporção de três mulheres para cada homem no acometimento dessa doença reumática. As médias das idades dos sujeitos das pesquisas indicam uma variação entre 48,4 anos e 65 anos, o que coincide com os dados da literatura para a incidência da doença: 40 a 60 anos (SILMAN; PEARSON, 2002).

Nas deformidades apresentadas e/ou problemas associados à $\mathrm{AR}$, foram encontrados: dor no punho $(5,6,7,8,10)$, deformidade em pescoço de cisne $(11,12)$, dedo em botoeira (2), desvio ulnar dos dedos (3), diminuição da destreza manual (1), sinais inflamatórios devido à artrite reumatoide inicial (9) e várias deformidades nas mãos não especificadas (4). Essas deformidades ratificam o que é descrito pela literatura para as indicaçôes das articulaçôes mais acometidas (ARAÚJO, 2006). Yasuda (2005)

Tabela 1. Caracterização da população.

\begin{tabular}{|c|c|c|c|}
\hline Estudo & $\begin{array}{c}\mathbf{N}^{\circ} \text { de } \\
\text { participantes }\end{array}$ & Média das idades & $\begin{array}{c}\text { Deformidades apresentadas e/ou } \\
\text { problemas associados }\end{array}$ \\
\hline $\begin{array}{l}\text { 1- Burtner et al. } \\
\text { (2003) }\end{array}$ & 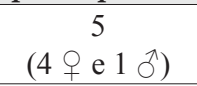 & 48,4 anos & Diminuição da destreza manual. \\
\hline $\begin{array}{l}\text { 2- Silva et al. } \\
\text { (2004) }\end{array}$ & $\begin{array}{c}20 \\
q\end{array}$ & $\begin{array}{c}25 \text { a } 74 \\
\text { (Limite de idade } \\
\text { dos participantes) }\end{array}$ & Dedo em botoeira. \\
\hline
\end{tabular}

\begin{tabular}{|c|c|c|c|}
\hline $\begin{array}{l}\text { 3- Noordhoek e } \\
\text { Barbosa (2004) }\end{array}$ & 4 & N.A.** & Desvio ulnar dos dedos. \\
\hline $\begin{array}{l}\text { 4- Zijlstra, } \\
\text { Heijnsdijk- } \\
\text { rouwenhorst e } \\
\text { Rasker ( 2004) }\end{array}$ & $\begin{array}{c}15 \\
(\text { maioria }+ \text { +)* }\end{array}$ & 65 & $\begin{array}{c}\text { Vários tipos de deformidades nos dedos, sem } \\
\text { especificar. }\end{array}$ \\
\hline $\begin{array}{l}\text { 5- Pagnotta et al. } \\
\text { (2005) }\end{array}$ & 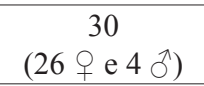 & 56,7 & $\begin{array}{c}\text { Dor no punho, baixa resistência, dificuldade no } \\
\text { desempenho da tarefa e no trabalho. }\end{array}$ \\
\hline $\begin{array}{l}\text { 6- Noordhoek e } \\
\text { Loschiavo (2007) }\end{array}$ & 1 & N.A.** & $\begin{array}{c}\text { Dor no punho decorrente da fase aguda da artrite } \\
\text { reumatoide. }\end{array}$ \\
\hline $\begin{array}{l}\text { 7- Veehof et al. } \\
\text { (2008a) }\end{array}$ & 33 & 60,3 & $\begin{array}{l}\text { Dor no punho, diminuição da força de preensão } \\
\text { e capacidade funcional. }\end{array}$ \\
\hline $\begin{array}{l}\text { 8- Silva et al. } \\
\text { (2008) }\end{array}$ & $\left.\begin{array}{c}47 \\
(\text { maioria }\end{array}\right)^{*}$ & $\begin{array}{c}18 \text { a } 65 \\
\text { (Limite de idade } \\
\text { dos participantes) }\end{array}$ & $\begin{array}{l}\text { Dor nas mãos e punho, incapacidade funcional, } \\
\text { força de pinça e preensão reduzidas, e } \\
\text { insatisfação do paciente. }\end{array}$ \\
\hline $\begin{array}{l}\text { 9- Adams et al. } \\
\text { (2008) }\end{array}$ & $\begin{array}{c}120 \\
(84 \stackrel{+}{+} \text { e } 32 \text { o }) \\
\end{array}$ & 57,4 & $\begin{array}{l}\text { Sinais inflamatórios devido à artrite reumatoide } \\
\text { inicial. }\end{array}$ \\
\hline $\begin{array}{l}\text { 10- Veehof et al. } \\
\text { (2008b) }\end{array}$ & $\begin{array}{c}20 \\
\text { (maioria }+ \text { )* }\end{array}$ & 56,3 & Dor no punho. \\
\hline $\begin{array}{l}\text { 11- Van der } \\
\text { Giesen et al. } \\
\text { (2009) }\end{array}$ & 47 & 53,8 & Pescoço de cisne. \\
\hline $\begin{array}{l}\text { 12- Vander } \\
\text { Giesen et al. } \\
\text { (2010) }\end{array}$ & $\begin{array}{c}50 \\
(41 \stackrel{+}{\mathrm{e}} 9 \text { ठ })\end{array}$ & 53,8 & Pescoço de cisne. \\
\hline
\end{tabular}

$\left(\right.$ maioria $q$ ) ${ }^{*}=$ Maioria do sexo feminino sem identificar o quantitativo. ${ }^{* * N}$ N.A.= Não abordado no artigo. 
aponta a segunda e a terceira metacarpofalangeanas da mão como as articulaçóes mais acometidas na $\mathrm{AR}$, seguidas de interfalangeanas proximais, punho e cotovelo.

Foi possível analisar que a dor no punho foi o problema mais relatado nos estudos revisados. O acometimento nessa articulação pelo pannus sinovial gera a destruição das estruturas do punho e da mão, e pode levar, progressivamente, à subluxação volar e ulnar, além de discreta supinação do punho. Isso é percebido no paciente pela falta de alinhamento entre o antebraço e a mão, com uma saliência da cabeça da ulna (ARAÚJO, 2006). A deformidade no punho traz um prejuízo na produção de movimentos de flexão, extensão e desvios radial e ulnar. Esses movimentos limitam a habilidade do paciente de manipular, posicionar e usar objetos, como, por exemplos, abrir uma torneira, torcer um pano e abrir um pote (ELUI; OLIVEIRA; SANTOS, 2001).

O desvio ulnar dos dedos - outra deformidade encontrada nesse estudo de revisão - ocorre por um direcionamento oblíquo dos tendóes flexores e dos extensores, formando com o eixo do dedo uma angulação ulnar, com contratura em flexão das metacarpofalangeanas e subluxação/luxação ventral da primeira falange. Esse desvio afasta o polegar dos outros dedos, dificultando a realização de pinça polpa a polpa, impossibilitando ao paciente segurar, por exemplo, objetos, como uma folha de papel ou uma moeda (SAURON, 2003; ARAUJO, 2006).

A deformidade em pescoço de cisne, apresentada em dois estudos $(11,12)$, se caracteriza por uma hiperextensão de interfalangeana proximal (IFP) com flexáo de interfalangeana distal (IFD). Essa deformidade pode ocorrer em três articulaçôes digitais: na IFD, IFP e na metacarpofalangeana (MCF). Na IFD, ocorre por um afrouxamento ou ruptura do tendão terminal do aparelho extensor, na IFP, pelo flexor superficial ser rompido pela tenossinovite dos flexores ou pelo afrouxamento da cápsula volar, e, por último, na $\mathrm{MCF}$, que ocorre pela contratura dos intrínsecos. Esses acometimentos vão causar um desequilíbrio dos extensores, afetando os movimentos de preensão (ARAÚJO, 2006).

A deformidade dedo em botoeira (2) se caracteriza pela flexão da IFP e pela hiperextensão da IFD, não sendo uma deformidade que causa muitos transtornos funcionais, se comparada às outras deformidades, mas também resulta em um desequilíbrio dos extensores, como na deformidade pescoço de cisne (ARAÚJO, 2006).

$\mathrm{O}$ acometimento na artrite reumatoide caracteriza-se pela simetria em relação a ambos os lados do corpo, assim como a cada articulaçáo acometida (O’DELL, 2008). Dessa forma, é comum que as atividades bimanuais apresentem-se, com a progressão da doença, gravemente afetadas. No universo das áreas de ocupação, o vestir, por exemplo, pode estar comprometido, pois a simples tarefa de abotoar camisas pode ser feita de forma muito dolorosa ou até mesmo ser incapaz de fazer.

A Tabela 2 - caracterização do estudo - registra o objetivo do estudo, os métodos, os tipos de órteses, o material, o tempo de uso e o papel do Terapeuta Ocupacional. Todas as metodologias utilizadas nos estudos, seja relato de caso ou estudo de caso-controle, possuem níveis de evidência científica diferenciadas, ou seja, os delineamentos dos estudos que lhes dão origem, a intensidade dos efeitos observados em cada estudo e a possibilidade de ocorrência de erros aleatórios são diversos, dependendo do tipo de metodologia utilizada (PEREIRA; BACHION, 2006). Apesar disso, todas permitem, em certo grau, contribuir para a tomada de decisão clínica do profissional e auxiliar na comprovaçáo da efetividade do uso de cada órtese.

A maioria dos estudos (75\%) tem como objetivo avaliar a eficácia da órtese, divulgando os benefícios e limitaçôes no uso desse dispositivo mecânico. Os demais se referem a um estudo que descreveu a confecção da órtese (6), outro correlacionou destreza manual e a eletromiografia (1), e outro verificou as dificuldades na função manual por conta da deformidade pescoço de cisne (12). Verifica-se que as órteses mais utilizadas foram: órtese de punho $(1,5,7,10)$, órtese para dedo $(2,3,4,11,12)$ e órtese de repouso $(6,8,9)$.

A órtese de punho, utilizada nos estudos 1, 5, 7 e 10, é confeccionada para imobilizar o punho, deixando-o em posição neutra ou em até $20^{\circ}$ de extensão. Esta não restringe os movimentos de pinça e é muito utilizada nos casos em que o processo inflamatório está ativo, pois ela imobiliza a articulação, gera repouso articular e reduz a dor e a inflamação (VEEHOF et al., 2008a; WASSERSTEIN, 2010).

A órtese de repouso, encontrada em três estudos $(6,8,9)$, imobiliza ventralmente punho, metacarpofalangeanas e interfalangeanas dos dedos; diminui forças externas ao corpo, promovendo a proteção articular e a cicatrização das estruturas lesionadas. Normalmente, é indicada para pacientes que estáo na fase aguda da doença e que precisam de repouso nas articulaçóes acometidas (RODRIGUES, 2002 apud NOORDHOEK; LOSCHIAVO, 2007). Esse tipo de órtese mantém a posição funcional da mão e equilibra a tensão entre os flexores e extensores extrínsecos dos dedos, mas não permite nenhuma 


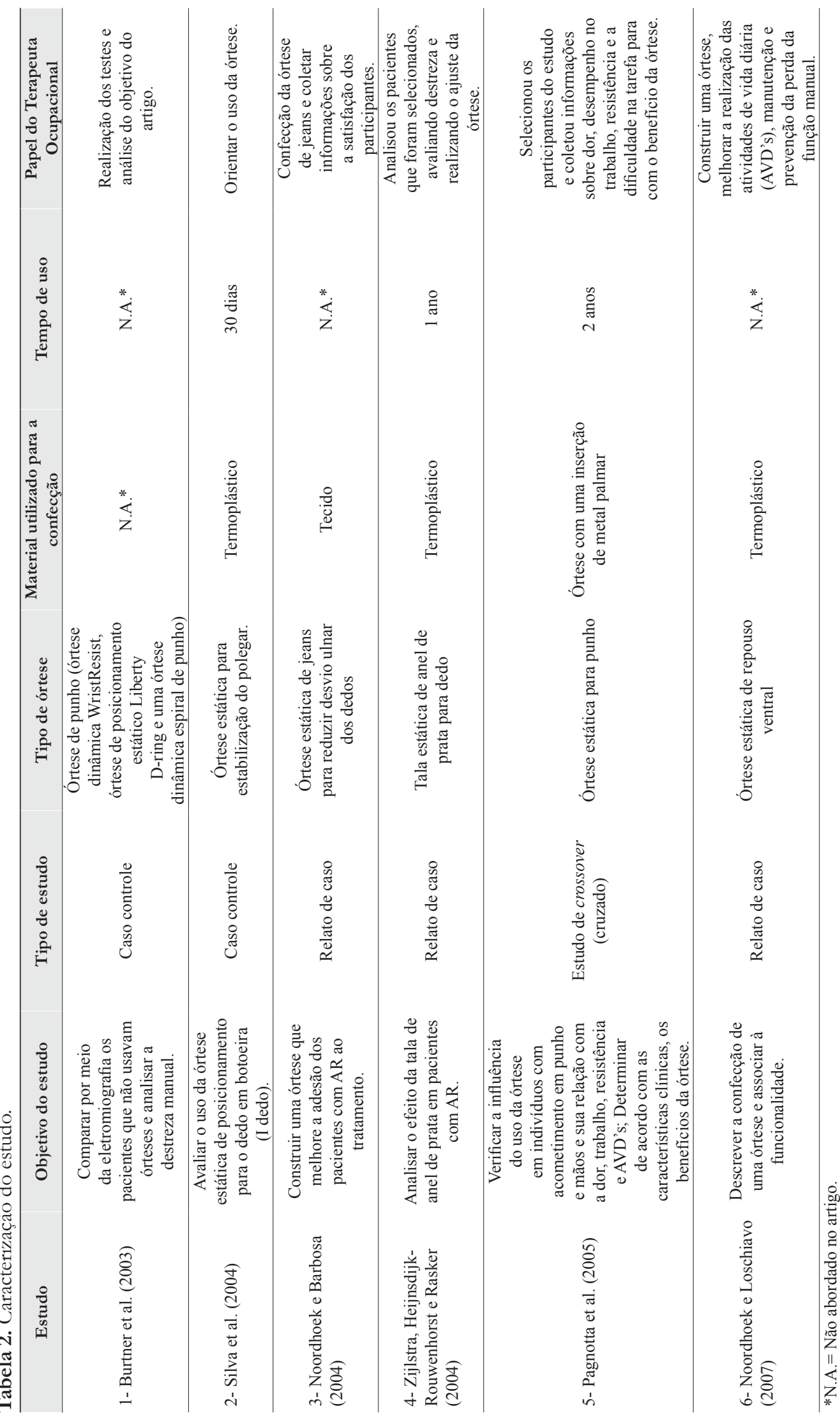




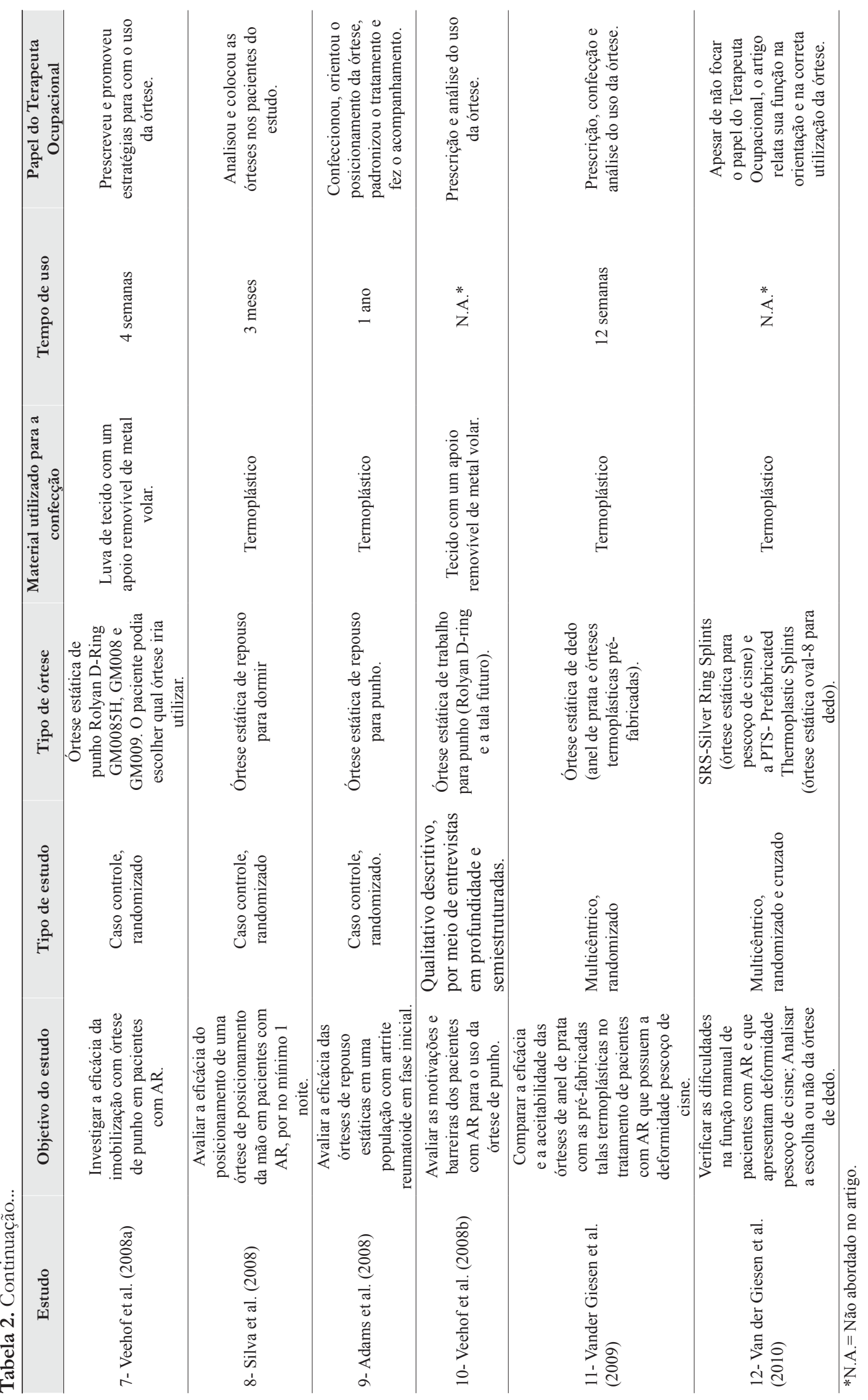


função manual (CARVALHO, 2006b). No estudo de Silva et al. (2008), foi pedido aos pacientes que usassem somente na hora de dormir. Esse repouso na articulação, após os três meses de intervenção, promoveu uma redução do processo inflamatório e diminuição da dor, o que permitiu melhora para realização das atividades cotidianas.

Já as órteses utilizadas para os dedos foram: órtese para o desvio ulnar dos dedos (3), estabilização do polegar (2), tala de anel de prata para dedo $(4,11)$, órtese para pescoço de cisne (12) e tala oval-8 para dedo (12). A órtese para desvio ulnar dos dedos serve para tracionar os dedos para seu alinhamento central e é útil para combater a tendência que as articulaçôes metacarpofalangeanas (MCF) têm em aumentar o desvio ulnar durante atividades que requerem preensão (GILBERT-LENEF, 1994 apud NOORDHOEK; BARBOSA, 2004). Em um dos estudos, essa órtese foi feita em jeans. Esse tipo de material é mais confortável e evita pontos de pressão nos espaços interdigitais e nas falanges proximais, facilitando a adesão do paciente ao uso desse dispositivo mecânico (NOORDHOEK; BARBOSA, 2004).

$\mathrm{Na}$ órtese para estabilizaçáo do polegar, a metacarpofalangeana fica alinhada e a interfalangeana do polegar fica em flexão, o que proporciona uma melhora na preensão polpa a polpa. Ela garante a estabilidade, mas pode dificultar a capacidade de utilizar a preensão grossa para manipulação de objetos maiores (SILVA et al., 2004).

A tala de anel de prata tem a função de impedir a hiperextensão e permitir a flexão da interfalangeana proximal, buscando melhora da destreza e da função manual. É uma órtese muito indicada para a deformidade em pescoço de cisne (ARAÚJO, 2006; VAN DER GIESEN et al., 2009). Por fim, a órtese SRS (Silver Ring Splints), que também é utilizada em pescoço de cisne, e a tala oval-8 para dedo, diminuem a flexão da IFD e a hiperextensão da IFP, o que leva a um alinhamento articular e à manutenção da função manual (BEASLEY, 2007; VAN DER GIESEN et al., 2010).

O material utilizado em $58,3 \%$ dos estudos foi o termoplástico de baixa temperatura $(2,4,6,8,9,11,12)$. Os outros materiais utilizados foram: tecido $(3,5,7,10)$, sendo que um dos artigos náo abordou o material utilizado na confecção (1). Segundo Carvalho (2006a), os termoplásticos de baixa temperatura se caracterizam pela facilidade na confecção da órtese, pois esta pode ser moldada no próprio corpo do paciente. Outra vantagem no uso desse tipo de material é a boa memória do material, que permite remodelamento à medida que o quadro clínico altera e possibilita pequenos ajustes durante a confecção.
Noordhoek e Barbosa (2004) utilizaram o jeans na confecção da órtese para diminuição do desvio ulnar dos dedos. Essa confecção em tecido melhorou a adesão dos participantes, se comparada com as órteses feitas de termoplástico de baixa temperatura que eles utilizavam anteriormente, pois relataram movimentos mais livres, firmeza ao realizar as atividades cotidianas, alívio da dor, a facilidade em lavar, além do fato de não esquentar durante o uso.

O cuidado na confecção das órteses em relação às áreas de pressão é primordial para o tratamento do paciente. Uma órtese sem ajuste adequado pode levar a pontos de pressão e produzir feridas, bem como pode comprometer as condiçóes de nutrição daquelas regiôes. Para a confecçáo da órtese de jeans, os cuidados se dirigem para os espaços interdigitais, para as falanges proximais e os lados laterais e mediais das metacarpofalangeanas (FERRIGNO, 2007).

$\mathrm{Na}$ Tabela 2, verifica-se que as órteses estáticas são encontradas em $100 \%$ dos estudos. Um único estudo (1) fez uso de três tipos de órteses: duas dinâmicas e uma estática (BURTNER et al., 2003).

As órteses estáticas são mais adequadas à população de pacientes com AR, pois atendem às necessidades dessa clientela, ao fornecer suporte às articulaçóes, ou arcos da mão ou área da mão; imobilizar nos casos de dor, inflamação e edema; promover alinhamento correto das articulações, e proteger músculos fracos (ELUI; OLIVEIRA; SANTOS, 2001). Nos estudos, o foco era no realinhamento articular, no suporte para as articulaçóes, bem como no repouso para diminuir o processo inflamatório e, por conseguinte, a dor no paciente.

Em relação ao tempo de uso da órtese, $41,6 \%$ dos estudos não informaram esse tempo $(1,3,6,10,12)$. As pesquisas têm duração mínima de 30 dias (2) e máxima de dois anos (5), porém, no estudo que durou 30 dias, há uma observação do autor relatando que este é um tempo pequeno para avaliar um resultado (SILVA et al., 2008). O tempo de uso é fundamental para avaliar a efetividade das órteses e a melhora funcional esperada.

Sauron (2003) aponta que o terapeuta ocupacional é o profissional mais apto a indicar e confeccionar as órteses. Em todas as pesquisas do resultado, este profissional estava diretamente ligado ao uso da órtese, seja para confecção, orientação ou acompanhamento da utilização. A terapia ocupacional se destacou nos estudos pelo seu papel na orientação e análise do uso da órtese.

É importante destacar que, nessa atribuição que é dada ao profissional, estão embutidas responsabilidades necessárias para a prescrição e a indicação de órteses (SAURON, 2003). É de 
responsabilidade do Terapeuta Ocupacional ter o conhecimento da anatomia funcional, no que se refere à função motora, ao revestimento cutâneo, ao sistema musculoesquelético e à função sensitiva. Ainda são necessários os conhecimentos dos tipos de materiais e características disponíveis no mercado; a seleção da órtese que irá atender às necessidades daquele paciente; a responsabilidade em orientar antes, durante e após a confecção, e até mesmo contraindicar órteses que não irão trazer benefícios ao paciente (SAURON, 2003).

A Tabela 3 descreve os desfechos dos estudos, quando aborda a eficácia em relação ao uso das órteses, nas diferentes deformidades de membro superior, além de um artigo abordar os cuidados após a confecção de uma órtese e outro retratar a atividade muscular pela eletromiografia após a utilização da órtese. Os efeitos do uso das órteses, muitas vezes, são aferidos por instrumentos de avaliação.

O estudo 6 (NOORDHOEK; LOSCHIAVO, 2007) se ateve a descrever sobre a confecção de um tipo de órtese, mas os demais estudos, para mensurar a eficácia das órteses, associam o uso da órtese a um resultado relacionado ao domínio "Funções do Corpo" e/ou ao domínio "Atividade e Participaçáo", da Classificação Internacional de Funcionalidade, Incapacidade e Saúde (ORGANIZAÇÃO..., 2003).

Os aspectos positivos encontrados na revisão de literatura foram: alívio da dor $(3,7,8,10,11)$, melhora na força de preensão ou de pinça $(1,2,7,8)$, melhora na destreza $(1,4,11)$ e facilidade no uso, conforto e boa aparência $(3,12)$.

A dor é um dos sintomas comuns nesses pacientes por conta do processo inflamatório característico da doença e da evoluçáo com deformidades $(3,7,8,10,11)$. O uso de órtese no alinhamento e estabilidade de articulações está associado à melhora do quadro álgico pela imobilizaçáo que proporciona (DE CARLO et al., 2004). No estudo 7, o teste utilizado para avaliar a dor foi a EVA (Escala Visual Analógica) e os pacientes fizeram uso da órtese por um mês; assim, foi reaplicada a EVA, que retratou uma diminuição 32\% na dor (VEEHOF et al., 2008b). A magnitude da dor é indicada pela percepção do paciente. Essa avaliação (também utilizada nos estudos 2,5 e 8) se destina a mensurar aspectos referentes ao domínio "Funçôes do Corpo" (funçóes sensoriais e dor) da CIF (ORGANIZAÇÃO..., 2003). Além da diminuição da dor, houve relato de melhora na força de preensão (VEEHOF et al., 2008b).

Já o estudo 9 utilizou uma avaliação funcional para mensurar a dor (ADAMS et al., 2008). O Michigan Hand Outcomes Questionnair (MHQ) está relacionadoà "Atividade e Participação" da CIF (ORGANIZAÇÃO...,
2003). Também utilizado no estudo 11 (VAN DER GIESEN et al., 2009), o MHQ é um questionário composto de 67 questōes que abrangem: função global, atividade de vida diária, dor, desempenho no trabalho, estética e a satisfação em relaçáo à funcionalidade da mão. No estudo 9, não houve diferenças significativas com relação ao nível de dor, porém, no grupo que utilizou a órtese, ocorreu uma diminuição da rigidez matinal (ADAMS et al., 2008).

A melhora na força de pinça ou de preensão é apontada nos estudos 1, 4, 7, 8 e 11 como um dos benefícios do uso da órtese (BURTNER et al., 2003; ZIJLSTRA; HEIJNSDIJK-ROUWENHORST; RASKER, 2004; SILVA et al., 2008; VEEHOF et al., 2008a; VAN DER GIESEN et al., 2009). As forças de preensão e/ou pinça foram medidas pelos dinamômetros Jammar e Pinch Gauge (FERRIGNO, 2007). Essa avaliação mensura aspectos relacionados à "Funçôes do Corpo" da CIF, no campo das funções neuromusculoesqueléticas e relacionadas a movimento (ORGANIZAÇÃO..., 2003).

Esse instrumento de mensuração é altamente recomendável pela alta confiabilidade apresentada (KASCH; NICKERSON, 2005; FERRIGNO, 2007). Através desse instrumento, pode-se medir a força de preensão palmar (pelo Jammar) e força das pinças polpa a polpa, lateral e trípode (pelo Pinch Gauge). É importante destacar que a dor, normalmente presente em pacientes com artrite reumatoide, pode influenciar no esforço voluntário máximo durante o teste (FERRIGNO, 2007). Na pesquisa 8, além dos testes para preensão e pinça, foi utilizado o EVA para mensuração do quadro álgico (CARVALHO; BÉRTOLO, 2008).

Os estudos não se ativeram a mensurar somente questôes de força muscular ou presença/ausência de dor. Os estudos 8, 9 e 11 e as pesquisas 8 e 7 utilizaram, respectivamente, os testes funcionais HAQ (Health Assessment Questionnaire) e DASH (Disabilities of the Arm, Shoulder and Hand), para avaliar o benefício obtido pelo paciente com o uso da órtese nas atividades funcionais (ADAMS et al., 2008; SILVA et al., 2008; VEEHOF et al., 2008b; VAN DER GIESEN et al., 2009). O HAQ avalia a dificuldade que o indivíduo possui na realização de atividades, como se vestir, acordar, alimentar-se, andar e realizar a higiene pessoal (NUNES, 2007). Já o DASH é composto por 30 itens que avaliam as atividades de vida diária e oito itens na área de lazer e trabalho. Tem como objetivo mensurar a incapacidade física e os sintomas dos membros superiores em indivíduos com determinada patologia (NUNES, 2007). 
Tabela 3. Resultados do estudo.

\begin{tabular}{ccc}
\hline Estudo & $\begin{array}{c}\text { Instrumentos de } \\
\text { mensuração }\end{array}$ & \multicolumn{1}{c}{ Resultado } \\
\hline 1- Burtner et al. (2003) & $\begin{array}{c}\text { Foi notável que a força de preensão pode ser diminuída; } \\
\text { porém, no uso da órtese em espiral, há melhora da pinça } \\
\text { e destreza sem diminuir a preensão. Não houve mudanças } \\
\text { na atividade muscular por conta do uso da órtese. Na } \\
\text { eletromiografia, foi possível analisar que os participantes } \\
\text { realizaram menor força com o uso da órtese, mas a } \\
\text { atividade muscular na realização das tarefas era igual. }\end{array}$ \\
\hline 2- Silva et al. (2004) & $\begin{array}{c}\text { Escala Visual Analógica } \\
\text { e O'Connor Functional } \\
\text { Evaluation. }\end{array}$ & $\begin{array}{c}\text { A órtese promove um aperfeiçoamento na pinça polpa a } \\
\text { polpa, beneficiando a melhora funcional. É confortável e } \\
\text { satisfaz os pacientes. }\end{array}$ \\
\hline
\end{tabular}

3- Noordhoek e Barbosa

(2004)

N.A*
Foi relatado que os movimentos da mão ficaram melhores, a órtese dá mais firmeza na realização das atividades, alivia a dor, é fácil de lavar e não esquenta ao

uso.
4- Zijlstra, Heijnsdijk-

Rouwenhorst e Rasker (2004)

- Pagnotta et al. (2005)
Sequential Occupational

Dexterity Assessment, Arthritis Impact

Measurement Scale 2, dinamômetro e Pinch Gauge.
Houve melhora na destreza, porém a força de preensão não melhorou, o que foi previsto por conta das deformidades já instaladas.

Não houve grandes melhoras no uso da órtese para a realização das tarefas, tais como aspirar a casa, elevar um jarro, cortar um alimento com a faca, levantar uma pasta, Escala Visual virar uma torneira, puxar um cabo elétrico, rodar a chave, Analógica. apertar um botão e empurrar um carrinho de compras. A única atividade que obteve uma avaliação favorável foi a que utilizava uma faca para cortar um alimento, na qual, nesse caso, a órtese foi benéfica.

\begin{tabular}{|c|c|c|}
\hline $\begin{array}{l}\text { 6- Noordhoek e } \\
\text { Loschiavo(2007) }\end{array}$ & N.A* & $\begin{array}{l}\text { Construiu e orientou a utilização de uma órtese para o } \\
\text { repouso articular. }\end{array}$ \\
\hline 7- Veehof et al. (2008a) & $\begin{array}{l}\text { Escala Visual } \\
\text { Analógica, } \\
\text { dinamômetro, } \\
\text { Disabilities of the Arm, } \\
\text { Shoulder and Hand e } \\
\text { Sequential Occupational } \\
\text { Dexterity Assessment. }\end{array}$ & $\begin{array}{l}\text { Foi avaliado que, no grupo das órteses, a dor diminuiu } \\
32 \% \text { e a força de preensão aumentou } 5 \% \text {. Já no grupo } \\
\text { controle, a dor aumentou } 17 \% \text { e a força de preensão } \\
\text { diminuiu } 8 \% \text {. A capacidade funcional melhorou } \\
\text { nos dois grupos, porém não obteve uma pontuação } \\
\text { significativamente diferente. As órteses de punho tiveram } \\
\text { um resultado satisfatório e retrataram que são eficazes na } \\
\text { redução de dor em pacientes com AR no punho. }\end{array}$ \\
\hline
\end{tabular}

Escala Visual

Analógica, Health

Assessment

8- Silva et al. (2008)

Questionnaire,

Disabilities of the Arm,

Shoulder and Hand,

JAMAR e Pinch Gauge.

Michigan Hand

9- Adams et al. (2008)

Outcomes Questionnair

e Health Assessment

Questionnaire.
As órteses proporcionaram um ganho de força de preensão e força de pinça, diminuíram dor, diminuindo também o processo inflamatório, o que obteve a satisfação dos participantes.

O uso de órtese na artrite reumatoide em fase inicial não proporcionou benefícios adicionais ao tratamento da terapia ocupacional, por ser muito cedo para intervir com a tala.

As órteses provocaram redução da dor, da sensação de formigamento, do inchaço e da inflamação, além de melhora na capacidade funcional. Apesar de apresentar melhora na capacidade funcional, alguns pacientes indicaram como pontos negativos para a órtese o fato de esta se molhar, sua aparência e a facilidade em se sujar. 
Tabela 3. Continuação...

\begin{tabular}{|c|c|c|}
\hline Estudo & $\begin{array}{c}\text { Instrumentos de } \\
\text { mensuração }\end{array}$ & Resultado \\
\hline $\begin{array}{l}\text { 11- Vander Giesen et al. } \\
\qquad(2009)\end{array}$ & $\begin{array}{c}\text { Health Assessment } \\
\text { Questionnaire, } \\
\text { Sequential Occupational } \\
\text { Dexterity Assessment, } \\
\text { JAMAR, Pinch Gauge, } \\
\text { Arthritis Impact } \\
\text { Measurement Scale } \\
\text { 2 e Michigan Hand } \\
\text { Outcomes Questionnair. }\end{array}$ & $\begin{array}{c}\text { Ambas as órteses melhoraram a destreza e reduziram a } \\
\text { dor. }\end{array}$ \\
\hline $\begin{array}{l}\text { 12- Van der } \\
\text { Giesen et al.(2010) }\end{array}$ & $\begin{array}{l}\text { Sequential Occupational } \\
\text { Dexterity Assessment. }\end{array}$ & $\begin{array}{l}\text { O estudo abordou os prós e contras da utilização de } \\
\text { dois tipos de órtese: SRS e PTS. Para o uso da SRS, } \\
\text { o artigo aborda como pontos positivos o efeito da } \\
\text { órtese em facilidade no uso, conforto e boa aparência } \\
\text { ( } 32 \text { pessoas). Em relação aos pontos negativos, houve } \\
\text { relatos sobre incômodo das arestas da órtese que davam } \\
\text { pontos de pressão, machucavam e transpiração excessiva } \\
\text { (13 pessoas). Para os que usaram o PTS, os aspectos } \\
\text { positivos compreendiam facilidade no uso, conforto e } \\
\text { boa aparência ( } 24 \text { pessoas). Nos aspectos negativos, } \\
\text { destacam-se as arestas, arranhos, tala escorregadia e } \\
\text { presença de parestesia (26 pessoas). }\end{array}$ \\
\hline
\end{tabular}

*N.A.= Não abordado no artigo.

Esses instrumentos se destinam a mensurar os aspectos do domínio "Atividade e Participação" da CIF (ORGANIZAÇĀO..., 2003), pois avaliam a capacidade ou as limitaçôes para executar uma atividade e se envolver em situaçóes vitais. Isso vem ao encontro da proposta de atuação da terapia ocupacional, pois indica a capacidade e as dificuldades apresentadas durante o envolvimento nas áreas de ocupação. Na pesquisa 8 , foi relatado que o DASH retratou melhora na força e o HAQ apresentou um aumento significativo da capacidade para realizar tarefas cotidianas (SILVA et al., 2008). Os mesmos autores afirmam que o HAQ é um teste eficaz quando associado às escalas para mensuraçáo da dor.

A melhora na destreza manual aparece como desfecho nas pesquisas após o uso de órteses. Nos estudos 4 e 11, a destreza foi avaliada pelo teste SODA (Sequential Occupational Dexterity Assessment) e pelo AIMS2 (Arthritis Impact Measurement Scales 2) (ZIJLSTRA; HEIJNSDIJK-ROUWENHORST; RASKER, 2004; VAN DER GIESEN et al., 2009). O SODA é composto por 12 tarefas do cotidiano, tais como copiar uma frase, pegar um envelope, pegar uma moeda, segurar o fone no ouvido, desenroscar a tampa de um tubo, lavar e enxugar as máos. O participante tem de classificar a tarefa executada e assim são analisadas a destreza bimanual e a dor na realizaçấo da atividade (OKU; PINHEIRO; ARAÚJO, 2009).
O AIMS2 é um questionário que avalia as funções do bem-estar físico, emocional e social. $\mathrm{O}$ paciente indica a frequência para realizar as atividades cotidianas. Esse instrumento de avaliação tem sido o mais abrangente para avaliar o estado de saúde global de uma pessoa com artrite reumatoide (BRANDÂO; FERRAZ; ZERBINI, 1997).

No estudo 4, a partir da avaliaçâo funcional, foi feita a prescriçáo do uso de uma órtese de anel de prata para dedos em 15 participantes que possuíam diferentes deformidades causadas pela AR. Após um ano de uso, detectou-se melhora na destreza, com aumento de nove pontos ou mais no instrumento de avaliação do SODA. A melhora manual também é relatada no AIMS2 (ZIJLSTRA; HEIJNSDIJK-ROUWENHORST; RASKER, 2004).

No estudo 1, utilizou-se o Nine-Hole Peg para avaliar a destreza (BURTNER et al., 2003). É um instrumento em que o paciente tem que encaixar e retirar os pinos dos buracos durante nove rodadas. A pontuação é dada pelo tempo gasto na realização da tarefa. Os autores avaliaram que, quando os indivíduos utilizavam a órtese dinâmica em espiral de punho, reduziam, significativamente, o tempo gasto para completar o Nine-Hole Peg, em comparação àqueles que usavam a órtese de posicionamento estática Libert D-ring (órtese de punho).

A satisfação do paciente e o conforto apresentado pelo uso da órtese são apontados em dois estudos 
$(3,12)$ como benefícios adquiridos no uso das órteses (NOORDHOEK; BARBOSA, 2004; VAN DER GIESEN et al., 2009). Na pesquisa 12 , foram relatados aspectos positivos, como a facilidade no uso, o conforto e a boa aparência (VAN DER GIESEN et al., 2009). Nesse estudo, 47 pacientes foram divididos em dois grupos: um utilizando a SRS (Silver Ring Splints) e o outro, a PTS (Prefabricated Thermoplastic Splints). O estudo não destacou qual a melhor órtese indicada para o uso, entretanto relatou uma eficácia similar, em termos de vantagens e desvantagens de cada uma (VAN DER GIESEN et al., 2010). A aparência da órtese e o conforto de usar um dispositivo que não esquenta ao uso também foram citados como pontos positivos do uso da órtese em pacientes com artrite reumatoide (NOORDHOEK; BARBOSA, 2004).

Em contrapartida aos benefícios apresentados, um dos estudos não apresenta pontos positivos relacionados ao uso da órtese (estudo 9) e justificou que o uso desse dispositivo mecânico, na fase inicial da AR, não confere benefícios adicionais ao tratamento $\mathrm{da}$ terapia ocupacional em relação à melhora na dor e na função, e em prevenir e/ou diminuir deformidades (ADAMS et al., 2008).

Nessa revisão, verifica-se que aspectos negativos foram apontados nos resultados, como a náo melhora na força de preensão (4) e os incômodos relacionados à utilização da órtese (12) A não melhora na força de preensão (4) foi constatada pelo uso do dinamômetro (ZIJLSTRA; HEIJNSDIJK-ROUWENHORST; RASKER, 2004). Segundo os autores, essa conclusão foi justificada pelas inúmeras deformidades já instaladas e que impediam a realização dos movimentos de preensão. Nos casos em que as deformidades já estão bem instaladas, de forma a produzir incapacidades para execução de atividades da rotina do paciente, a terapia ocupacional recorre a adaptaçóes (DE CARLO et al., 2004).

No estudo 12, com o intuito de comparar duas órteses (SRS e a PTS), aponta-se que os aspectos negativos relacionados ao uso dessas órteses se referem a incômodos nas arestas, machucados, transpiração excessiva, tala escorregadia e presença de parestesia (VAN DER GIESEN et al., 2010). Os mesmos autores analisaram que a PTS obteve mais aspectos negativos que a SRS, porém nenhum paciente foi contra o uso de nenhum dos tipos de órteses, pois os aspectos positivos sobrepóem-se aos negativos. As órteses melhoraram a qualidade de vida dos sujeitos da pesquisa, bem como a satisfaçáo com relação ao uso. Segundo Shipham (2003) e Assumpção (2006), para evitar esses efeitos negativos, ao confeccionar uma órtese, é importante saber distribuir a pressão, utilizar a tensão adequada, eliminar fricção e realizar ajustes, se necessário. É preciso atender às necessidades funcionais e biomecânicas individuais .

$\mathrm{Na}$ clínica da terapia ocupacional, as órteses são ferramentas de trabalho muito utilizadas, seja para auxiliar no melhor posicionamento do membro superior, seja para incrementar alguma função manual (AGNELLI; TOYODA, 2003; VEEHOF et al., 2006; OLIVEIRA et al., 2010). Considerando-se que a artrite reumatoide pode trazer prejuízos funcionais de magnitudes diversificadas e com forte impacto social e econômico, o uso da órtese é apontado na revisão de literatura como um beneficiador de uma série de desfechos relacionado às "Funções do Corpo", bem como "Atividade e Participaçáo" da CIF (ORGANIZAÇĀO ..., 2003). Isso demonstra que os estudos estão em consonância com o objetivo central preconizado pela terapia ocupacional, pois a revisão aponta para uma preocupação com as habilidades de desempenho do paciente, bem como com a autonomia e/ou a independência para se engajar nas diversas áreas de ocupação.

\section{Considerações finais}

É comum que pessoas diagnosticadas com artrite reumatoide tenham, na maioria das vezes, problemas articulares e/ou periarticulares. Muito presentes em membros superiores, os problemas estáo intimamente relacionadas à capacidade de o paciente se manter independente em seu desempenho ocupacional.

Com o aparecimento ou a progressão das deformidades, a função manual no paciente apresenta-se limitada no que se refere a força, destreza, amplitude de movimento, bem como à capacidade de posicionar e utilizar as mãos nas diversas atividades funcionais. Nesse contexto, a órtese surge como um recurso de tecnologia assistiva importante para a manutençáo da função e o resgate das atividades que estavam comprometidas.

Mesmo com a escassez de estudos na literatura, foi possível detectar que o uso das órteses é favorável para a realização das atividades de vida diária (básicas ou instrumentais), lazer e trabalho, uma vez que os resultados apresentaram melhora na capacidade funcional dos indivíduos. Os participantes se sentiram satisfeitos em relação a diminuição da dor, aumento de força de preensão ou pinça e prevenção da progressão das deformidades, e com a melhora da movimentação das articulaçôes do membro superior que estavam afetadas pela doença. 


\section{Agradecimentos}

Ao Instituto Federal de Educação, Ciência e Tecnologia do Rio de Janeiro (IFRJ), por sempre estimular a pesquisa.

\section{Referências}

ADAMS, J. et al. The clinical effectiveness of static resting splints in early rheumatoid arthritis: a randomized controlled trial. Rheumatology, London, v. 47, n. 10, p. 1548-1553, 2008. http://dx.doi.org/10.1093/rheumatology/ken292. PMid:18701540.

AGNELLI, L. B.; TOYODA, C. Y. Estudo de materiais para a confecçấo de órteses e sua utilizaçáo prática por terapeutas ocupacionais no Brasil. Cadernos de Terapia Ocupacional da UFSCar, São Carlos, v. 11, n. 2, p. 8394, 2003.

ARAÚJO, P. M. P. Reabilitação da mão reumatoide. In: FREITAS, P. P. Reabilitação da mão. São Paulo: Atheneu, 2006. p. 379-394.

ASSUMPÇÃO, T. S. Órteses: princípios básicos. In: FREITAS, P. P. Reabilitação da mão. São Paulo: Atheneu, 2006. p. 539-553.

BEASLEY, J. Arthritis. In: COOPER, C. Fundamentals of hand therapy: clinical reasoning and treatment guidelines for common diagnoses of the upper extremity. United State: Elsevier, 2007. p. 457-478.

BRANDÃO, L.; FERRAZ, M. B.; ZERBINI, C. A. F. Avaliação da qualidade de vida na artrite reumatóide: revisão atualizada. Revista Brasileira de Reumatologia, São Paulo, v. 37, n. 5, p. 275-281, 1997.

BRASIL. Portaria no 710, de 27 de junho de 2013. Aprova o Protocolo Clínico e Diretrizes Terapêuticas da Artrite Reumatoide. Diário Oficial [da] República Federativa do Brasil, Poder Executivo, Brasília, DF, 27 jun. 2013. Disponível em: <http://bvsms.saude.gov.br/ bvs/ saudelegis/sas/2013/prt0710_27_06_2013.html>. Acesso em: 08 ago. 2013.

BRASIL. Secretaria Especial dos Direitos Humanos. Coordenadoria Nacional para Integração da Pessoa Portadora de Deficiência. Ata - VII Reunião do Comitê de Ajudas Técnicas-CAT CORDE/SEDH/PR realizada nos dias 13 e 14 de dezembro de 2007. Disponível em: <http:// www.infoesp.net/CAT_Reuniao_VII.pdf $>$. Acesso em: 12 dez. 2013.

BUCKNER, W. S. Artrite. In: PEDRETTI, L. W.; EARLY, M. B, Terapia Ocupacional: capacidades práticas para as disfunçôes físicas. São Paulo: Roca, 2005. p. 847-874.

BUENO, V. C. et al. Reabilitação em artrite idiopática juvenil. Revista Brasileira de Reumatologia, Sáo Paulo, v. 47, n. 3, p. 197-203, 2007.

BURTNER, P. A. et al. A Comparison of static and dynamic wrist splints using electromyography in individu- als with rheumatoid arthritis. Journal of Hand Therapy, New York, v. 16, n. 4, p. 320-325, 2003.

CARVALHO, J. A. Classificação das órteses. In: CARVALHO, J. A. Órteses: um recurso terapêutico complementar. São Paulo: Manole, 2006a. p. 17-24.

CARVALHO, J. A. Órteses para membros superiores. In: CARVALHO, J. A. Órteses: um recurso terapêutico complementar. São Paulo: Manole, 2006b. p. 147-157.

CARVALHO, M. A.; BÉRTOLO, M. B. Artrite Reumatóide. In: DE CARVALHO, M. A.; LANNA, C. C. D.; BÉRTOLO, M. B. Reumatologia: diagnóstico e tratamento. Sáo Paulo: Gen, 2008. p. 311-328.

CAVALCANTI, M. P. Levantamento estatístico dos pacientes atendidos pela ADORE (Associação dos Portadores de Doença Reumática. 2006. 44 f. Monografia (Bacharel em Fisioterapia) - Universidade Tuiuti do Paraná, Curitiba, 2006.

DE CARLO, M. M. R. P. et al. Terapia Ocupacional em Reumatologia: Princípios e Perspectivas. In: DE CARLO, M. M. R. P.; LUZO, M. C. M. Terapia ocupacional: reabilitaçáo física e contextos hospitalares. São Paulo: Roca, 2004. p. 153-182.

EGAN, M. et al. Splints and orthosis for treating rheumatoid arthritis (review). London: The Cochrane Colaboration, 2010. Disponível em: <http://www.bibliotecacochrane.com/PDF/CD004018.pdf>. Acesso em: 08 ago. 2013 .

ELUI, V. M. C.; OLIVEIRA, M. H. P.; SANTOS, C. B. Órtese: um importante recurso no tratamento da mão em garra móvel de Hansenianos. Hansen International, Lexington, v. 26, n. 21, p. 105-111, 2001.

FERRIGNO, I. S. V. O uso de órteses em Terapia de mão. In: FERRIGNO, I. S. V. Terapia de mão: fundamentos para a prática clínica. São Paulo: Gen, 2007. p. 123-137.

KASCH, M. C.; NICKERSON, E. Lesões nas mãos e nos membros superiores. In: PEDRETTI, L. W.; EARLY, M. B. Terapia ocupacional: capacidades práticas para as disfunçóes físicas. São Paulo: Roca, 2005. p. 875-910.

LAURINDO, I. M. M. et al. Artrite reumatoide: Diagnóstico e tratamento. Revista Brasileira de Reumatologia, São Paulo, v. 44, n. 6, p. 1-15, 2004.

NOORDHOEK, J.; BARBOSA, L. F. M. Órtese de jeans para desvio ulnar dos dedos. Revista Brasileira de Reumatologia, São Paulo, v. 44, n. 2, p. 150-151, 2004.

NOORDHOEK, J.; LOSCHIAVO, F. Q. Órtese de repouso para fase aguda de artrite reumatoide. Revista Brasileira de Reumatologia, São Paulo, v. 47, n. 2, p. 121 122, 2007.

NUNES, C. M. P. Métodos e técnicas de avaliação nas áreas de desempenho ocupacional. In: SOUZA, A. C. A.; GALVÃO, C. R. C. Terapia Ocupacional: fundamentaçáo e prática. Rio de Janeiro: Guanabara Koogan, 2007. p. 54-69. 
O’DELL, J. R. Artrite reumatoide: a doença - diagnóstico e manifestações clínicas. In: IMBODEN, J.; STONE, J.; HELLMANN, D. Current diagnóstico e tratamento: reumatologia. Sáo Paulo: Mc Graw Hill, 2008. p. 161169.

OKU, E. C.; PINHEIRO, G. R. C.; ARAÚJO, P. M. P. Instrumentos de avaliação funcional da mão em pacientes com artrite reumatoide. Fisioterapia em Movimento, Curitiba, v. 22, n. 2, p. 221-228, 2009.

OLIVEIRA, R. E. C. et al. Terapia Ocupacional. In: JARDIM, J. R.; NASCIMENTO, O. A. Guias de medicina ambulatórial e hospitalar da UNIFESP-EPM: reabilitação. São Paulo: Manole, 2010. p. 241-298.

ORGANIZAÇÃO MUNDIAL DA SAÚDE - OMS. Classificação Internacional de Funcionalidade, Incapacidade e Saúde. São Paulo: Edusp, 2003.

PAGNOTTA, A. et al. Static wrist splint use in the performance of daily activities by individuals with rheumatoid arthritis. The Journal of Rheumatology, Toronto, v. 32, n. 11, p. 2136-2143, 2005.

PEREIRA, A. L.; BACHION, M. M. Atualidades em revisão sistemática de literatura, critérios de força e grau de recomendação de evidência. Revista Gaúcha de Enfermagem, Porto Alegre, v. 27, n. 4, p. 491-498, 2006.

SAURON, F. N. Órteses para membros superiors. In: TEIXEIRA, E. et al. Terapia ocupacional na reabilitação física. São Paulo: Roca, 2003. p. 265-296.

SHIPHAM, M. Rheumatoid arthritis: hand function, activities of daily living, grip strength and essential assistive devices. Curationis, Durbanville, v. 26, n. 3, p. 98-106, 2003.

SILMAN, A. J.; PEARSON, J. E. Epidemiology and genetics of rheumatoid arthritis. Arthritis Research \& Therapy, London, v. 4, n. 3, p. 265-272, 2002. http:// dx.doi.org/10.4102/curationis.v26i3.857.

SILVA, A. C. et al. Effectiveness of a night-time hand positioning splint in rheumatoid arthritis: a randomized controlled trial. Journal of Rehabilitation Medicine, Uppsala, v. 40, n. 9, p. 749-754, 2008.

SILVA, P. G.; MEIRELES, S. M.; NATOUR, J. Reabilitação na artrite reumatoide. In: JARDIM, J. R.; NASCIMENTO, O. A. Guias de medicina ambulatorial e hospitalar da UNIFESP-EPM: Reabilitação. São Paulo: Manole, 2010. p. 435-441.
SILVA, S. N. P. et al. Orthesis' initial impact in rheumatoid arthritis patients with boutonnières deformity on the thumb. Revista Brasileira de Reumatologia, São Paulo, v. 44, n. 4, p. 311-316, 2004.

VAN DER GIESEN, F. J. et al. Effectiveness of two finger splints for swan neck deformity in patients with rheumatoid arthritis: a randomized, crossover trial. Arthritis \& Rheumatism, Malden, v. 61, n. 8, p. 1025 1031, 2009. ttp://dx.doi.org/10.1002/art.24866. PMid:1964489.

VAN DER GIESEN, F. J. et al. Swan neck deformities in rheumatoid arthritis: a qualitative study on the patients' perspectives on hand function problems and finger splints. Musculoskeletal Care, Malden, v. 8, n. 4, p. $179-188,2010$.

VEEHOF, M. et al. Possession of Assistive devices is related to improved psychological well-being in patients with rheumatic conditions. The Journal of Rheumatology, Toronto, v. 33, n. 16, p. 79-83, 2006.

VEEHOF, M. M. et al. Determinants of the use of wrist working splints in rheumatoid arthritis. Arthritis \& Rheumatism, Malden, v. 59, n. 4, p. 531-536, 2008 a. http://dx.doi.org/10.1002/art.23531. PMid:18383423.

VEEHOF, M. M. et al. Efficacy of wrist working splints in patients with rheumatoid arthritis: a randomized controlled study. Arthritis \& Rheumatism, Malden, v. 59, n. 12, p. 1698-1704, 2008b. http://dx.doi.org/10.1002/ art.24078. PMid:19035420.

WASSERSTEIN, S. Órteses para os membros superiores In: JARDIM, J. R.; NASCIMENTO, O. A. Guias de medicina ambulatórial e hospitalar da UNIFESP-EPM: reabilitação. São Paulo: Manole, 2010. p. 611-623.

WASSERSTEIN, S.; CHAMLIAN, T. R. Órteses. In: JARDIM, J. R; NASCIMENTO, O. A. Guias de medicina ambulatórial e hospitalar da UNIFESP-EPM: reabilitação. São Paulo: Manole, 2010. p. 583-610.

YASUDA, Y. L. Artrite reumatóide e osteoartrite. In: YASUDA, C. A.; RADOMSKI, M. V. Terapia Ocupacional para Disfunções Físicas. São Paulo: Santos, 2005. p. 1001-1024.

ZIJLSTRA, T. R.; HEIJNSDIJK-ROUWENHORST, L.; RASKER, J. J. Silver Ring Splints improve dexterity in patients with rheumatoid arthritis. Arthritis Care \& Research, Malden, v. 51, n. 6, p. 947-951, 2004.

\section{Contribuição dos Autores}

Lilian Dias Bernardo Massa e Talita Silvério de Souza Silva fizeram a busca dos artigos no banco de dados, leitura dos artigos e elaboração do texto com discussão dos resultados. 